
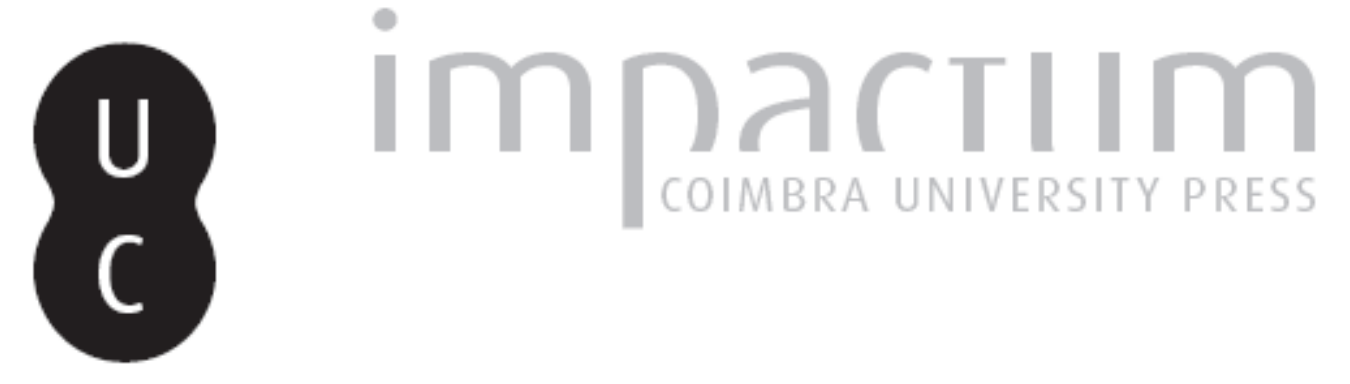

\title{
Modificações dentárias na primeira catedral do Brasil, Salvador, Bahia
}

\author{
Autor(es): $\quad$ Líryo, Andersen; Rodrigues-Carvalho, Claudia; Souza, Sheila Mendonça \\ de; Carvalho, Diana Maul de
}

Publicado por: CIAS - Centro de Investigação em Antropologia e Saúde

URL persistente:

URI:http://hdl.handle.net/10316.2/41276

DOI:

DOI:http://dx.doi.org/10.14195/2182-7982_18_6

Accessed : $\quad$ 26-Apr-2023 08:17:33

A navegação consulta e descarregamento dos títulos inseridos nas Bibliotecas Digitais UC Digitalis, UC Pombalina e UC Impactum, pressupõem a aceitação plena e sem reservas dos Termos e Condições de Uso destas Bibliotecas Digitais, disponíveis em https://digitalis.uc.pt/pt-pt/termos.

Conforme exposto nos referidos Termos e Condições de Uso, o descarregamento de títulos de acesso restrito requer uma licença válida de autorização devendo o utilizador aceder ao(s) documento(s) a partir de um endereço de IP da instituição detentora da supramencionada licença.

Ao utilizador é apenas permitido o descarregamento para uso pessoal, pelo que o emprego do(s) título(s) descarregado(s) para outro fim, designadamente comercial, carece de autorização do respetivo autor ou editor da obra.

Na medida em que todas as obras da UC Digitalis se encontram protegidas pelo Código do Direito de Autor e Direitos Conexos e demais legislação aplicável, toda a cópia, parcial ou total, deste documento, nos casos em que é legalmente admitida, deverá conter ou fazer-se acompanhar por este aviso.

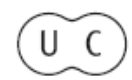


Antropologia Portuguesa

Volume $18 \cdot 2001$

Departamento de Antropologia | Universidade de Coimbra 


\title{
Modificações dentárias
}

\section{na primeira catedral do Brasil, Salvador, Bahia}

\author{
Andersen Liryo', Claudia Rodrigues-Carvalho' ${ }^{2}$, Sheila Mendonça de \\ Souza', Diana Maul de Carvalho'
}

'Núcleo de Estudos em Saúde Coletiva

Universidade Federal da Rio de Janeiro, Brasil

'Departamento de Antropologia do Museu Nacional

Universidade Federal do Rio de Janeiro, Brasil

'Departamento de Endemias da Escola Nacional de Saúde Pública

Fundação Oswaldo Cruz, Brasil

liryotobiwemail.com

Resumo Os restos esqueléticos humanos são uma importante fonte de informação para os arqueólogos. Hábitos e costumes como o da modificação dentária, prática que existiu em diversas partes do mundo, inclusive no Brasil, são passiveis de serem estudados a partir deste material. Nas escavações da antiga igreja da Sé de Salvador, Bahia, foram encontrados 44 dentes incisivos com modifícação intencional, numa série de 1289 dentes avulsos. Todos esses dentes foram encontrados em depósito secundário no adro da Sé. No presente trabalho apresentamos o estudo destes dentes modificados, cujas formas se assemelham a modificações encontradas tanto em grupos da África quanto da América, discutindo seu contexto e hipóteses explicativas para este achado.

Palavras-chave Paleopatologia; modificação dentária; antropologia dental; arqueologia histórica; Bahia.

Abstract Human skeleton remains are important archaeological sources of information. Cultural habits such as tooth modification, a practice described in different parts of the world including Brazil, can also be studied. During the archaeological excavations at the Sé church (XIX - XX century) of Salvador, Bahia, Brazil, 44 modified human incisors were found among 1289 commingled teeth of different kinds. All those teeth came from a secondary deposition area associated with the "adro" at the external front part of the church. The present paper describes those modified teeth whose morphologies are similar to those described for some African and American groups. The archaeological context and some hypothesis for the finding are discussed. 
Key words Paleopathology; tooth modification; dental anthropology; historical archaeology; Bahia.

\section{Introdução}

A paleopatologia é o estudo das doenças no passado feito através, principalmente, do exame dos restos esqueléticos humanos encontrados nos sitios arqueológicos. Este tipo de estudo se remete ao final do século XIX com os primeiros exames de múmias egípcias, feitos por pesquisadores como Hrdlicka, Jones, Virchow e outros, interessados na observação de marcadores patológicos mais aparentes, como as lesões traumáticas, inflamações, lesões líticas, etc (Buikstra e Cook, 1992).

Devido às características singulares da dentição, com sua estrutura e funções, seu contato imediato com o meio externo e com os alimentos (Gray, 1995), e a possibilidade de utilização da boca como uma "terceira mão", acabou por tornar o estudo dos dentes em populações pretéritas num subcampo especializado da paleopatologia, voltado para o entendimento das relações entre os processos de saúde/doença bucais e o contexto biocultural das populações estudadas, compreendendo neste caso, além das questões alimentares, práticas culturais de ação direta sobre a dentição (Rodrigues-Carvalho e Mendonça-de-Souza, 1998).

Este estudo também investiga sinais não patológicos no esqueleto, resultados de hábitos que podem agir como mediadores ou elementos importantes no processo de saúde/doença. Entre esses hábitos pode-se citar o uso de adornos labiais, que pode levar à perda precoce e/ou desgaste diferencial do dentes anteriores; ou as deformações cranianas e mutilações dentárias, praticadas por diferentes povos do "Novo" e "Velho Mundo", que podem levar a diversos quadros clínicos, inclusive ser a causa morte por septicemia, devido à exposição acidental da polpa dentária' na realização da modificação dos dentes (Cunha, 1969).

' Não há concordância entre os cientistas quanto ao uso dos termos Dental e Dentírio. Segundo Beker (1972), em latim o termo dentalis (dental) significa "peça de arado, onde se encaixa a relha"; e o adjetivo dentarius (dentário) é o único e exclusivo termo "relativo aos dentes". Por isso, neste trabalho adota-se o termo dentário, e suas variantes, para referências aos dentes. 
A prática da modificação dentária é encontrada em quase todos os continentes, tendo sido verificadas evidências em diversos paises africanos, como Angola, Congo, Nigéria, Moçambique, Sudão e Uganda (Pereira Filho, 1968); na Península Ibérica (Dembo e Imbelloni, 1938); no Japāo (Koganei, 1921-22); na região mesoamericana e andina (Fastlicht, 1948); e, em algumas tribos brasileiras (Cunha, 1968a; Lima, 1954).

Essa prática da modificação dos elementos dentários não é recente. Foram encontrados restos humanos do período neolítico, em tumbas e mastabas egípcias, e entre os Maias e outros povos pré-colombianos (Andrade, 1964). Até recentemente era possivel encontrar alguns povos africanos e índios brasileiros com o hábito de modificar seus dentes (Lima, 1954).

Cada autor a sua época tentou criar uma classificação para essas modificações dentárias, entre eles está Delfino (1948) que considerou que as "alterações dento-maxilares intencionais" poderiam ser classificadas em: "decoração dentária" (coloração e incrustação); "mutilação dentária" (total e parcial); e, "deformação maxilar" (pronasia). Todavia o uso do termo "decoração" sugere imediatamente uma finalidade estética, o que é questionável, em muitos casos, especialmente quando entendida como finalidade única da alteração. $\mathrm{Na}$ "incrustação", apesar da aplicação de algum material no local mutilado (jadeita, hematita, turquesa, cristais de rocha, ouro, etc), não há recomposição da estrutura original do dente, ou seja, a peça alterada permanece com sua estrutura abalada. E, apesar do termo "mutilação" ter sido consagrado pelos pesquisadores clássicos como Alfonso Dembo, Javier Romero e, do Brasil, o Professor Pedro Lima, esta expressão, também, implica um juízo estético e, mesmo, moral. Por isso, para evitar confusões terminológicas neste trabalho, preferiu-se adotar o termo "modificação" que abrange todas as ações intencionais executadas nos dentes, desde a coloração dos dentes com uma substância chamada betel, prática observada entre os índios americanos das Carolinas Ocidentais, até as elaboradas e refinadas incrustações, encontradas entre os Maias (Romero, 1958).

Os primeiros estudos sistemáticos das modificações dentárias intencionais começaram com E. T. Hamy, em 1882 (Nesi, 1969), estudando os casos encontrados na peninsula de Yucatán no México. No mesmo período, Ladislau Netto (Cunha, 1968b) publicou um trabalho sobre modificações dentárias observadas em 15 mil flagelados da seca que assolava os 
Estados nordestinos do vale do baixo São Francisco. Mas existem relatos anteriores feitas por cronistas, missionários e viajantes, referindo-se à prática de mutilar os dentes entre povos "primitivos". Por exemplo, o Frei João dos Santos, que missionou em Moçambique de 1596 a 1597, relata em seu livro Etiópia Oriental o hábito de mutilar os dentes visto em alguns povos desta região (Santos, 1962).

O presente trabalho apresenta a identificação das modificações encontradas em dentes humanos recuperados nas escavações da Sé Primacial do Brasil, no centro histórico de Salvador, Bahia (figura 1). Essa identificação constitui mais um elemento biocultural importante para a caracterização da população sepultada naquele sítio, contribuindo para a reconstituição do passado recente do Brasil.

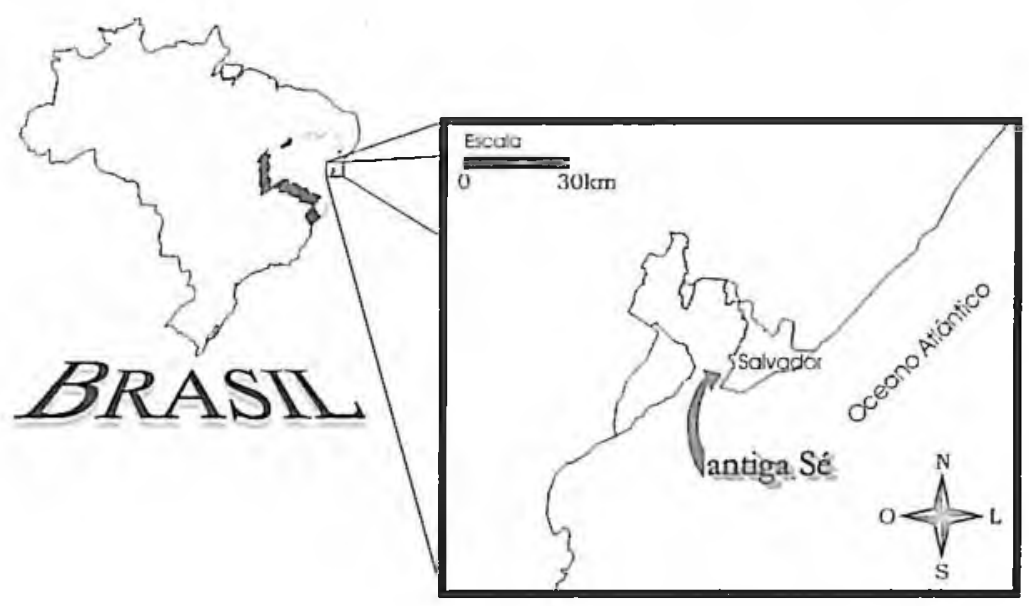

Figura 1. Localização da cidade de Salvador e, respectivamente, da antiga lgreja da Sé.

\section{A antiga Igreja da Sé}

No periodo de Julho de 1998 a Julho de 1999 foi executada em Salvador a primeira etapa de escavações da área originalmente ocupada pela primeira catedral do Brasil. O projeto tinha como uma das propostas a escavação dos alicerces dos quatro cantos do antigo prédio, para sua exposição permanente no novo layout que seria dado à Praça da Sé, em decorrência das comemorações dos 450 anos de Salvador. 
A antiga catedral, construída a partir de 1552 no governo de Thomé de Souza (Peres, 1974), localizava-se sobre as escarpas da cidade-alta, de frente para a Baia de Todos os Santos. Era uma igreja de grandes proporções, com decoração barroca, que sofreu modificações ao longo de sua história, muitas vezes, devido aos abalos em sua estrutura, causados pela movimentação do terreno em conseqüência do seu peso e do de prédios vizinhos (Carneiro, 1980).

Essa foi a primeira catedral, mas não foi a primeira igreja da Sé. Os jesuitas que vieram na armada de Thomé de Souza, para a fundação da cidade de Salvador, tinham a missão de erigir uma Sé provisória, construída também na parte alta da cidade, feita de taipa e coberta de palhas de palma, sob a invocação de Nossa Senhora da Ajuda (Peixoto, 1980).

A catedral chegou a ter, no século XVII, sua frontaria composta por duas torres, a do relógio e a do sino, e um frontispício de pedras brasileiras dotado de doze colunas (Boccanera, 1921). Com a expulsão dos jesuitas do Brasil no ano de 1759 , as atribuições da Sé passaram, em 1760 , para a igreja do antigo colégio dos jesuítas, deixando de ser catedral definitivamente em 1765 (Peixoto, 1980).

Em 1865, foi construída na área à frente da igreja, a mando do Desembargador Luis Barbosa de Almeida, a praça Dona Isabel, selando de vez o solo consagrado do adro onde foram enterradas centenas de pessoas (Boccanera, 1921). Em 1933, contra a vontade de toda a população e com o pretexto de ser em favor do progresso, a antiga catedral foi demolida, apesar da sua importância na história da cidade, senão do Brasil, e local de sepultamento de personagens de renome nacional (Barbosa, 1972).

\section{A pesquisa arqueológica}

A escavação da Sé foi dividida em setores, que não cobriram toda a área ocupada pela igreja, devido às grandes proporções e à proposta de exposição permanente das quinas do prédio (Etchevarne et al., 1999).

Além dos alicerces, as escavações evidenciaram restos materiais representativos do cotidiano da cidade, como os objetos de uso doméstico, de uso pessoal, lúdicos, bélicos, materiais construtivos, restos alimentares e, principalmente, restos esqueléticos humanos. Os sepultamentos foram encontrados apenas na parte da frente da igreja, tanto do lado de dentro 
(nave) quanto de fora (adro), nos setores A, B e F. No adro foi retirado o maior número de esqueletos do sítio e os mais bem preservados. Os sepultamentos da nave se mostraram fragmentados e com maior número de perturbações pós-deposicionais, a exemplo da colocação de redes elétricas, de telefonia e esgotamento sanitário (Etchevarne et al., 1999).

No setor F, correspondente ao adro, observou-se a existência de dois contextos arqueológicos distintos. O primeiro, mais próximo à igreja, ia desde a camada arqueológica mais superficial até o solo estéril a mais de 2 metros de profundidade. Este foi identificado como o solo original, o qual sofria um mergulho, formando um barranco em direção ao paredão da escarpa. O outro contexto estava localizado por sobre o solo anterior, entre a face do barranco e o limite da escarpa, tendo pouco mais de $2 \mathrm{~m}$ de profundidade em alguns pontos, e mostrava característica de um depósito secundário. Neste aterro não foram encontrados sepultamentos na primeira etapa de escavação, mas apenas fragmentos de esqueletos avulsos de vários indivíduos misturados a outros tipos de materiais. $\mathrm{O}$ achado de áreas de redeposição de enterramentos e ossuários não é incomum, na medida que em várias igrejas foram feitas limpezas e esvaziamentos para possibilitar a entrada de novos corpos (Reis, 1991). Assim sendo, o achado de ossos avulsos na área escavada permite supor tratar-se de material proveniente de antigos enterramentos remanejados, eventualmente misturados a deposições mais antigas existentes naquele local.

A mais antiga datação obtida para o sítio, através de amostras de cerâmica Tupiguarani coletadas no interior da igreja (setor D) é de $610 \pm 65$ anos $\mathrm{AP}^{2}$, feita no Laboratório de Física da Faculdade de Tecnologia de São Paulo. Essa datação antecede em mais de 200 anos à fundação da cidade, que se deu em 1549, e concorda com evidências arqueológicas da presença da Tradição Tupiguarani na região (Etchevarne et al., 1999).

Dessa forma é possível postular duas ocupações distintas da área, uma indígena, pré-colonial, representada pelos remanescentes cerâmicos e, eventualmente, por outros artefatos e possiveis restos esqueléticos humanos; e uma colonial, representada pela antiga Catedral da Sé, pelos

2 AP ou Antes do Presente refere-se ao ano de 1950, data base para a calibração dos processos de datação absoluta, especialmente do radiocarbono (Souza, 1997). 
sepultamentos nela depositados desde sua construção (dentro e fora do prédio) e por todos os artefatos relacionados a este contexto.

\section{Material}

A série estudada é formada por 1289 dentes humanos avulsos, de todos os tipos (incisivos, caninos, pré-molares e molares) e de ambas as arcadas, incluindo peças decíduas e permanentes. Destes, 44 dentes incisivos permanentes, superiores e inferiores, apresentaram algum traço de modificação coronária intencional (figura 2).

Todos os dentes modificados se encontravam desarticulados e avulsos, a exceção de um conjunto de quatro dentes superiores, tombados com o número Se.III.1248, que se encontrava desarticulado, mas associado a outros dentes e fragmentos da maxila de um mesmo indivíduo, para o qual foi possivel estabelecer a relação.

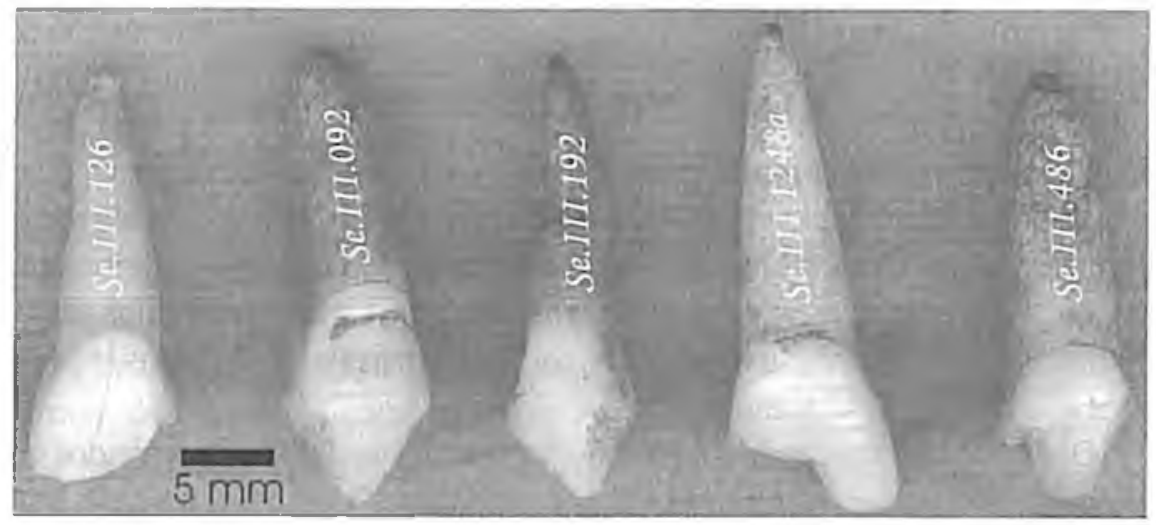

Figura 2. Cinco exemplares de dentes avulsos da igreja da Sé de Salvador, Bahia, Brasil, com modificaçāo intencional (Foto A. Líryo).

Em geral, apesar da modificação tornar a estrutura dentária mais frágil e mais suscetível à ação de fatores tafonômicos, o estado de preservação dos dentes é bom, a exceção de um exemplar tombado com o número Se.III.1065, no qual ocorreu degradação, principalmente, da raiz e da dentina sob o esmalte coronário. 


\section{Metodologia}

Inicialmente os dentes foram limpos com pincéis de pelos macios e esponjas umedecidas para remoção dos sedimentos aderidos, e foram numerados para registro e tombamento.

A seleção dos dentes modificados foi feita pelo exame direto das peças, a vistas desarmadas, com base nas modificações do contorno anatômico da coroa dentária. Um segundo exame mais detido dos dentes, feito com auxílio de lupa binocular (40X), serviu para confirmar o trabatho intencional de modificação, eliminando outros problemas como fraturas acidentais em vida e alterações tafonômicas. Este exame microscópico permitiu também a observação do desgastes causados pelo uso dos dentes sobre os bordos e faces mutiladas, no intuito de eliminar possiveis casos de modificação post mortem, e dos sinais remanescentes da técnica de modificação empregada, mais uma pista não biológica usada para tentar identificar a origem étnica do material, sem a pretensão de estender sua discussão.

Foram considerados como sinais de desgaste causados pelo uso dos dentes em vida o arredondamento dos bordos e pontas resultantes da modificação, com apagamento total ou parcial das cicatrizes deixadas pela técnica empregada na modificação. Foram consideradas como marcas da técnica mutilatória cicatrizes como os sulcos, linhas e estrias, deixadas por limagem, cortes ou fraturas abruptas e perpendiculares ao plano principal da coroa dentária, e marcas representadas por cicatrizes escalonadas, indicativas do uso de instrumento cortante, martelado seguidas vezes sobre a superficie do esmalte.

Os dentes selecionados mediante tais critérios foram desenhados e descritos de modo a compor um corpo de dados. O desenho de cada um dos incisivos mutilados foi feito observando a peça pela face vestibular e traçando-se apenas o contorno da modificação (figura 8). Para que fosse dado destaque às diferenças nos contornos mutilatórios, o desenho é esquemático, não representando os detalhes anatômicos de forma realista, do mesmo modo que foi feito por Romero (1958) no seu quadro classificatório.

Estes desenhos foram organizados em um quadro classificatório de acordo com as principais formas de modificações encontradas, a saber: retirada de um dos ângulos incisais; retirada dos dois ângulos incisais; 
modificação vestibular; estreitamento da coroa dentária (figura 3). Dentro de cada uma dessas categorias, os dentes foram alinhados no sentido crescente do seu número de tombo para facilitar a rápida localização de cada exemplar (figura 8 ).

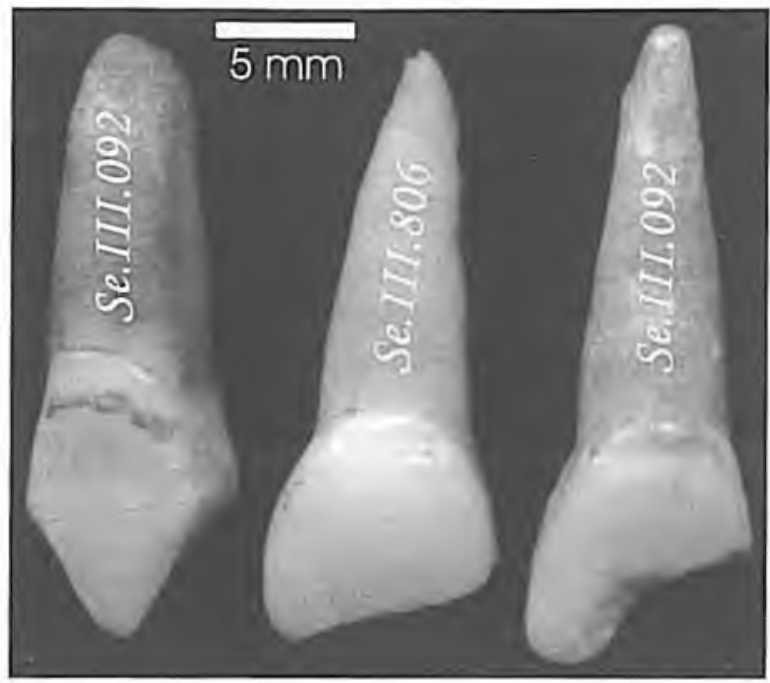

Figura 3. Tipos de modificações mais comuns nos dentes da antiga igreja da Sé, Salvador, Bahia. Da esquerda para a direita: retirada dos dois ângulos; retirada de um ângulo; recorte de um dos ângulos (Foto A. Líryo).

A descrição das peças baseou-se nos contornos das modificações, observadas pela face vestibular, como em Rubín de la Borbolla (1940). Porém, ela não pode ser mais detalhada por não se poder fazer a divisão da coroa em terços, devido à dificuldade em estabelecer estas porções em peças que já sofreram desgaste fisiológico e retirada intencional de partes da coroa.

Os dentes foram identificados apenas como superiores ou inferiores, já que a modificação prejudicou o exame do principal e mais seguro elemento de identificação den-

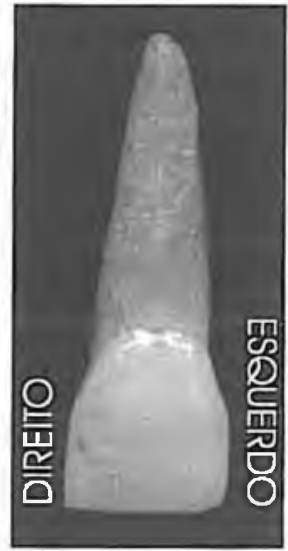

Figura 4. Indicação do lado da mutilação (Foto A. Líryo). 
tária, a coroa (Della Serra e Ferreira, 1981). Por esse mesmo motivo, não foi possível distinguir quais eram as faces interproximais mesial e distal. Assim, na descrição estes dois termos foram substituídos por direito e esquerdo (figura 4), sem implicar na identificação da lateralidade dos dentes, mas apenas na localização da modificação nas peças, observadas pela norma vestibular, e considerando-se os planos de referência anatômica do corpo onde situava-se o dente.

As formas de modificações encontradas foram comparados às descritas na literatura como prática mutilatória por diferentes etnias africanas (Dembo e Imbelloni, 1938; Delfino, 1948; Santos, 1962) e brasileiras (Lima, 1954; Cunha, 1968a; Cunha, 1968b; Nesi, 1969; Pereira Filho, 1968), tendo em vista estabelecer, de modo tentativo, proposições para uma identificação étnica com base no achado.

\section{Resultados}

Entre os 1289 dentes avulsos examinados, 354 eram incisivos, dos quais, $44(12,4 \%)$ apresentavam algum tipo de modificação intencional. Entre estes, 23 dentes (52,2\%) possuiam modificação pela retirada de um dos ângulos incisais, $19(43,2 \%)$ tinham a retirada dos dois ângulos, e mais dois casos singulares: a peça Se.III.193 $(2,3 \%)$ com estreitamento da coroa pelo desbaste de toda a altura das duas faces interproximais; e, Se.III.705 $(2,3 \%)$ com a modificação da face vestibular, pela feitura de sulcos transversais ao eixo longo da coroa dentária, associado à criação de uma incisura na porção média do bordo incisal (tabela 1).

Apesar de poder criar quatro conjuntos por tipos de modificação para os dentes mutilados da Sé, é necessário considerar que apesar do agrupamento, arbitrário como qualquer tentativa de classificação, observam-se variações nas formas mutiladas, que muitas vezes se devem às intercorrências casuais na execução da técnica, diferentes respostas dentárias à aplicação das forças de corte, fratura ou limagem, sobreposta por forças de desgastes posteriores, e assim por diante (figura 5).

Os tipos de modificações encontradas são semelhantes a alguns descritos por Romero (1958) para os povos ameríndios (do quadro classificatório de Romero existe semelhança com os tipos: B1, B4, B6, C1, C5, C6, F3 e F4), e por Dembo e Imbelloni (1938) para grupos negros de 
diversas partes da África, constituindo-se grande parte em formas simples e muito comuns de modificação, que consiste em apontar os dentes dando-lhes uma forma aproximadamente triangular pela excisão dos dois ângulos incisais ("dentes de piranha"), ou a criação de uma abertura triangular pela retirada dos ângulos adjacentes de dois incisivos vizinhos ("V invertido").

Tabela 1. Distribuição dos dentes por tipos de modificação na série da igreja da Sé de Salvador, Bahia, Brasil.

\begin{tabular}{|c|c|c|c|c|c|c|}
\hline \multirow{3}{*}{ Tipo de modificaçĩo } & \multicolumn{6}{|c|}{ Posiçũo anatômica } \\
\hline & \multicolumn{2}{|c|}{ superior } & \multicolumn{2}{|c|}{ inferior } & \multicolumn{2}{|c|}{ lotial } \\
\hline & $n$ & "ii & $\mathrm{n}$ & $\%$ & $N$ & $\because$ \\
\hline Retirada de um ảngulo & 16 & 36,3 & 7 & 15,9 & 23 & 52,2 \\
\hline Retirada de dois angulos & 15 & 34,1 & 4 & 9,1 & 19 & 43,2 \\
\hline Estreitamento da coroa & 0 & - & 1 & 2,3 & 1 & 2,3 \\
\hline Vestibular & 1 & 2,3 & 0 & - & 1 & 2,3 \\
\hline Total & 32 & 72,7 & 12 & 27.3 & 44 & 100 \\
\hline
\end{tabular}

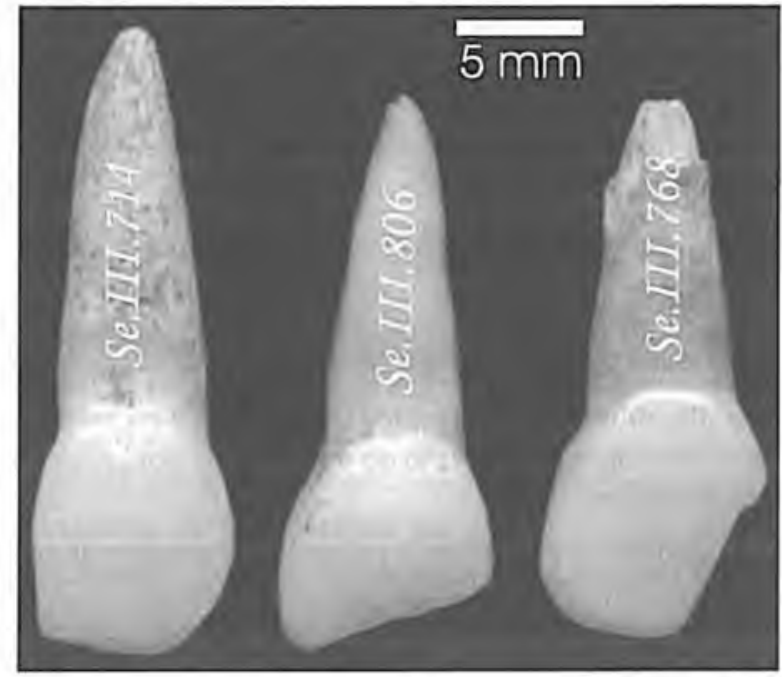

Figura 5. Três exemplares de dentes da igreja da Sé de Salvado, Bahia, Brasil, mostrando a variaçāo de um mesmo tipo de modificaçāo, a retirada de um dos ângulos incisais (Foto A. Liryo). 
Exceto o exemplar com modificação vestibular, forma diferente de qualquer outra modificação já referida, todas as outras peças $(97,7 \%)$ apresentam contornos mutilatórios compativeis com as modificações africanas, principalmente no que diz respeito ao recorte do contorno menos acabado que aqueles observados entre os ameríndios, tal como propõem Dembo e Imbelloni (1938).

Para os mesmos tipos de modificações, observamos variações no formato de seus contornos, existindo ou não intencionalidade nessa produção. Uma dessas diferenças foi a da preservação ou não do bordo incisal após a retirada de um ou de ambos os ângulos incisais. Como comparativos, pode-se tomar o exemplo da peça Se.III.224, sem preservação do bordo incisal, e das peças Se.III.444 e Se.III.486, com preservação (figura 6).

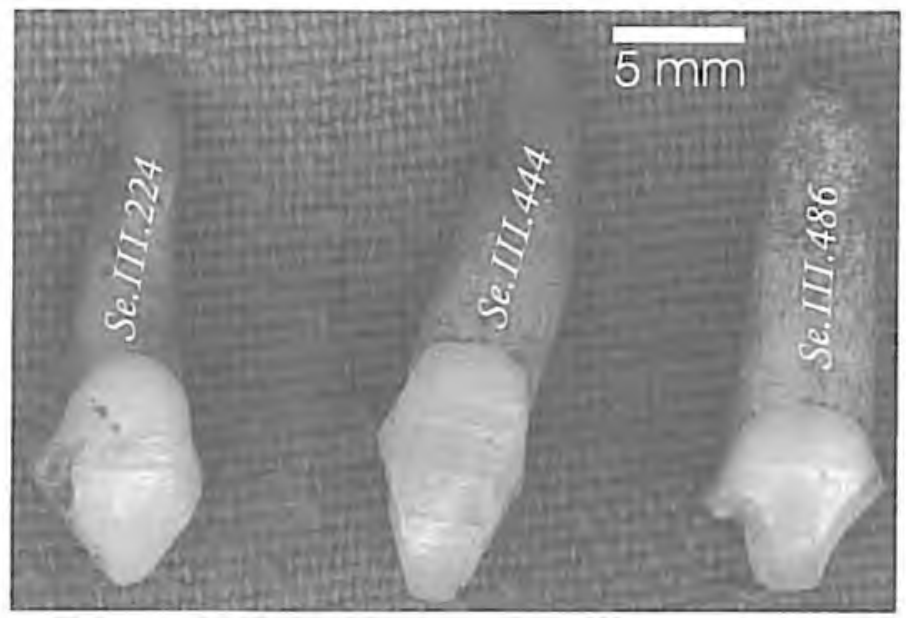

Figura 6. Três exemplos mostrando a retirada completa e a preservação de parte do bordo incisal na modificação do mesmo tipo (Foto A. Líryo).

No caso dos dentes que tiveram a retirada de um dos ângulos pela criação de um contorno angular, sete exemplares no total - tombados com os números, Se.III.359, Se.III.759, Se.III.1065, Se.III.1248a, Se.III.1248b, Se.III.1248c, Se.III.1248d -, todos conservaram parte do bordo incisal, o mesmo ocorrendo com exemplar que teve a coroa estreitada e aquele que teve sua face vestibular mutilada (tabela 2). 
Tabela 2. Distribuição da preservação do bordo incisal na série de dentes avulsos mutilados da igreja da Sé, Salvador, Bahia (excluídos os dentes com modificaçāo angular, vestibular ou estreitamento da coroa).

\begin{tabular}{|c|c|c|c|c|c|c|}
\hline \multirow{3}{*}{ Tipo de modificação } & \multicolumn{6}{|c|}{ Bordo incisal] } \\
\hline & \multicolumn{2}{|c|}{ parte preservado } & \multicolumn{2}{|c|}{ nāo preservado } & \multicolumn{2}{|c|}{ Total } \\
\hline & $\mathbf{n}$ & is & $n$ & $\%$ & $\mathrm{~N}$ & 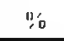 \\
\hline Retirada de um ângulo & 7 & 15,9 & 16 & 36,3 & 23 & 48,6 \\
\hline Reliradil de dois angulos & 11 & 25,0 & 8 & 18,2 & 19 & 51,3 \\
\hline Estrcitamento da coroa & - & - & 1 & 2,3 & 1 & 2,3 \\
\hline Vestibular & - & - & 1 & 2,3 & 1 & 2,3 \\
\hline Total & 18 & 40,9 & 26 & 59,1 & $\overline{44}$ & 100 \\
\hline
\end{tabular}

Outra variação notada, e que não se pode afirmar quanto a sua intencionalidade, foi quanto ao desenho do contorno das faces mutiladas (tabela 3). O mais comum de todos foi o contorno com recorte em linha reta, freqüente tanto nas modificações pela retirada de um ângulo quanto na extração dos dois ângulos incisais. Outros tipos de contornos observados foram os de recorte sinuoso, côncavo e convexo. Em sete casos de retirada dos dois ângulos $(36,8 \%)$, pode-se notar que a mesma peça apresentava um tipo de recorte para cada face criada pela modificação. E, em outros oito casos de toda a série $(18,2 \%)$, as modificações terminavam em uma saliência na forma de uma ombreira, perto da porção cervical do dente, o que poderia ser decorrente da

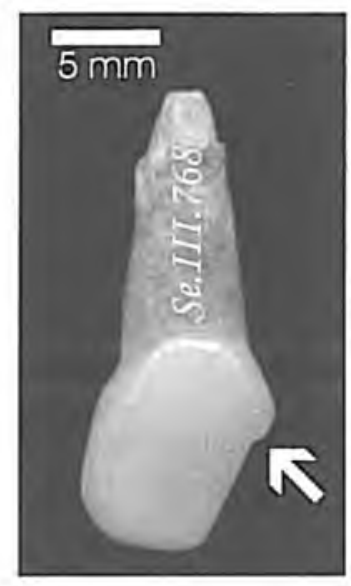

Figura 7. Modificação terminada em uma ombreira

(Foto A. Líryo). imperícia do executor, da própria técnica aplicada, ou simplesmente da conformação anatômica que impunha restrições à profundidade do trabatho modificador (figura 7). As variações no padrão mutilatório podem ser vistas na figura 8 . 
Tabela 3. Distribuição dos tipos de recorte presentes, com exceção da modificaçāo vestibular, considerando-se todas as faces dentais criadas pela modificaçāo (em algumas peças podem ocorrer duas faces mutiladas).

\begin{tabular}{|c|c|c|c|c|c|c|}
\hline \multirow[t]{2}{*}{ Tipo de recorte } & \multicolumn{4}{|c|}{ Posiçāo anatomica } & \multirow[b]{2}{*}{ total } & \multirow[b]{2}{*}{$\because 0$} \\
\hline & superior & $\because$ & inferior & 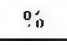 & & \\
\hline Reto & 25 & 39,7 & 13 & 20,6 & 38 & 60,3 \\
\hline Sinuoso & 6 & 9,5 & 2 & 3,2 & 8 & 12,7 \\
\hline Côncavo & 5 & 7,9 & 0 & - & 5 & 7,9 \\
\hline Convexo & 4 & 0,3 & 1 & 1,6 & 5 & 7,9 \\
\hline Angular & 6 & 9,5 & 1 & 1,6 & 7 & 11,1 \\
\hline Tolal de recortes & 46 & 73,0 & 17 & 27,0 & 63 & 100 \\
\hline
\end{tabular}

A título de uma primeira análise exploratória, poderia-se dizer que entre os dentes que sofreram a retirada de apenas um dos ângulos incisais, no total de 23 peças, ocorreu uma pequena vantagem no número de extrações do ângulo direito, principalmente dos dentes superiores (tabela 4). A verificação desta freqüência só é relevante para se ter uma idéia da localização das modificações, mas sem ter como identificar a precisa localização anatômica dos dentes, não é possivel saber se há uma tendência para se extrair os ângulos mesiais ou distais, informação que nos daria mais uma pista do padrão mutilatório presente na série antropológica da Sé.

Tabela 4. Distribuição das modificaçōes em dentes com retirada de um dos ângulos incisais de acordo com a lateralidade.

\begin{tabular}{|c|c|c|c|c|c|c|}
\hline \multirow[t]{2}{*}{ Posiçã̃o anatōmica } & \multicolumn{6}{|c|}{ Lado da modificação } \\
\hline & direito & 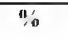 & espuerdo & $\frac{1}{9}$ & total & "in \\
\hline Superior & 10 & 43,5 & 6 & 26,1 & 16 & 69,6 \\
\hline Inferior & 3 & 13,0 & 4 & 17,4 & 7 & 30,4 \\
\hline Total & 13 & 56,5 & 10 & 43,5 & 23 & 100 \\
\hline
\end{tabular}

No exame microscópico foram encontrados 39 dentes $(88,6 \%)$ com cicatrizes, decorrentes da técnica de modificação aplicada (tabela 5). Desses, $14(35,9 \%)$ tinham sulcos com formato fusiforme, cujo eixo longo 
orientava-se na direção vestíbulo-lingual, sugerindo a retirada por lascamento sucessivo do ângulo. Apenas o exemplar Se.III.1088, representando $2,5 \%$ das peças com cicatrizes, apresentou finas estrias com direção vestibulo-lingual na face criada pela retirada do ângulo incisal direito, sugerindo que neste caso a modificação teria se dado por limagem.

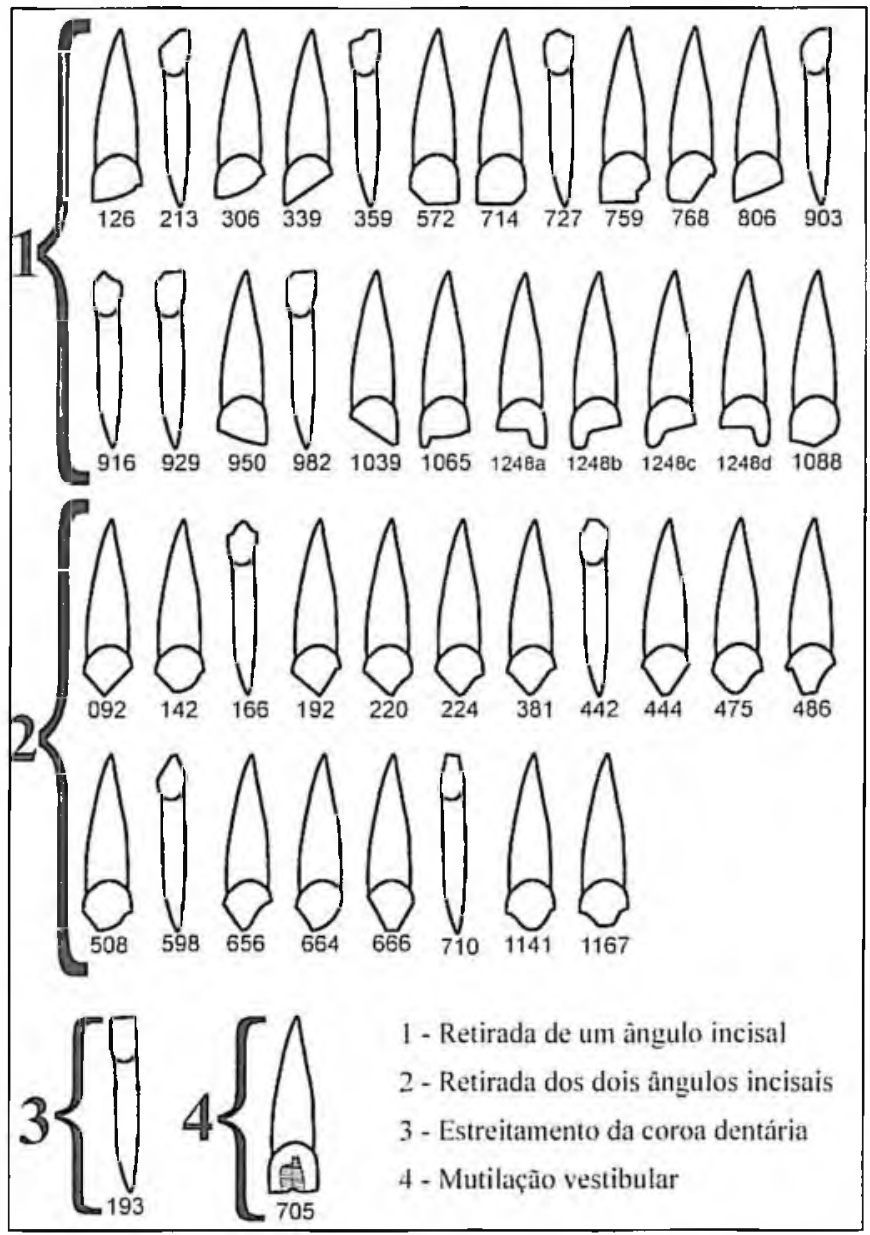

Figura 8. Quadro com representação esquemática dos dentes avulsos mutilados encontrados na antiga igreja da Sé de Salvador, Bahia, Brasil, identificados com seus respectivos números de tombo, e agrupados de acordo com os tipos de mutilação.

Os dentes inferiores estão representados com a coroa para cima (A. Líryo). 
Tabela 5. Distribuição das marcas observadas nas faces de modificação, indicativas do tipo de técnica aplicada na execuçāo do trabalho modificador.

\begin{tabular}{|c|c|c|c|c|c|c|c|c|}
\hline \multirow{3}{*}{$\begin{array}{c}\text { Posição } \\
\text { anatômica }\end{array}$} & \multicolumn{8}{|c|}{ Tipos de cicatrizes } \\
\hline & \multirow{2}{*}{$\begin{array}{c}\text { Sulcos } \\
\text { fusilormes }\end{array}$} & \multicolumn{3}{|c|}{ estrias } & \multirow{2}{*}{$\begin{array}{c}\text { outras } \\
\text { cícatrizes }\end{array}$} & \multicolumn{3}{|c|}{ total } \\
\hline & & $\because{ }^{\prime}$ & & $\because$ & & $\%$ & & $O_{0}^{\prime}$ \\
\hline Superior & 12 & 30,8 & 1 & 2,5 & 17 & 43,6 & 30 & 76,9 \\
\hline Inferior & 2 & 5,1 & - & - & 7 & 18,0 & 9 & 23,1 \\
\hline Total & 14 & 35,9 & 1 & 3,5 & 24 & 61,6 & 39 & 100 \\
\hline
\end{tabular}

Marcas de desgaste fisiológico foram vistas em 42 dentes $(95,4 \%)$, atingindo tanto as pontas e bordas criadas pela modificação quanto na dentina exposta. Foram também encontradas 14 peças $(31,8 \%)$ com depósitos de cálculo dentário nas faces modificadas, um indicador de valor semelhante ao desgaste, pois mostra que o indivíduo sobreviveu à modificação e que ela não foi feita post mortem (tabela 6). Na única peça com modificação vestibular (Se.III.705, figura 8) pode-se observar que o desenho formado tem dois lados distintos, separados por uma fissura central. No lado direito observou-se a presença de seis sulcos transversais e no esquerdo foram vistos oito sulcos, todos com fundo irregular.

Tabela 6. Distribuição dos depósitos de cálculo e de desgaste nas faces mutiladas, indicando sobrevida e continuidade do uso dos dentes após a modificaçāo.

\begin{tabular}{|c|c|c|c|c|}
\hline \multirow{2}{*}{ Posição anatômica } & \multicolumn{4}{|c|}{ Indicador de sobrevida } \\
\hline & Depósito de cálculo & $\%$ & Desgaste & !ú \\
\hline Superior & 12 & 27,3 & 30 & 68,2 \\
\hline Inferior & 2 & 4,5 & 12 & 27,3 \\
\hline Total & 14 & 31,8 & 42 & 95,5 \\
\hline
\end{tabular}

\section{Discussão}

São várias as circunstâncias nas quais diversos povos mutilam seus dentes, entre elas está a definição de uma identidade étnica, a demarcação de status ou casta, a estética, a proteção mágica, a profilaxia de doenças e 
assim por diante (Delfino, 1948). Todavia, a modificação não é feita de maneira aleatória ou seguindo escolhas individuais, padrões socioculturais específicos a cada grupo determinam o tipo ou os diferentes tipos de modificações feitas, quais os dentes a serem mutilados, a técnica empregada e qual o padrão associativo entre as formas.

Por outro lado, sabe-se que existem formas de modificações dentárias semelhantes compartilhadas por diferentes etnias. Este é o caso, por exemplo, da retirada de um dos ângulos incisais - conhecido como "V invertido" - e o dos dois ângulos - chamado de "dente de piranha". Além disso, a associação entre diferentes formas mutiladas na boca de um mesmo indivíduo, ou o conjunto de dentes que são mutilados, pode ser igual entre diferentes etnias (Romero, 1958), o que torna a distinção entre eles com base apenas no exame de dentes, em alguns casos, muito dificil.

Em peças avulsas, como as da Sé, não é possivel saber quais eram os padrões combinatórios, não só porque não se têm as peças montadas nas arcadas, mas também porque não se sabe exatamente de quais povos elas se originaram. Com exceção do conjunto Se.III.1248 (figura 9), composto por quatro dentes incisivos superiores escavados na mesma quadra e profundidade, juntamente com outros dentes e fiagmentos da maxila do mesmo individuo, não é possível propor as associações em que tais formas mutiladas seriam encontradas. A proposição de inferência étnica, neste caso, baseia-se no exame das formas dos dentes, associada às marcas deixadas pela técnica usada na modificação, e a consideração do contexto histórico-arqueológico dos achados.

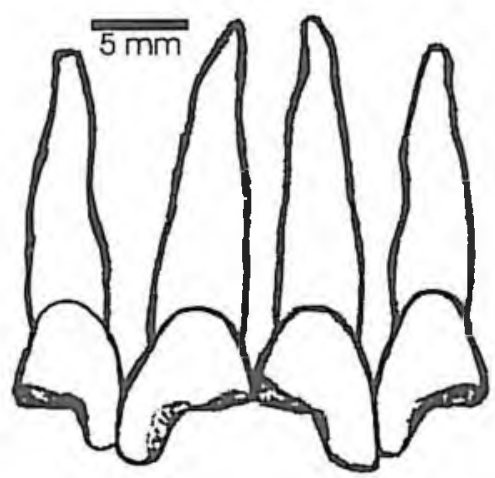

Figura 9. Conjunto "Se.III.1248", formado pelos quatro incisivos superiores de um mesmo indivíduo. 
Sabe-se que em Salvador os enterros em igreja e seus arredores foram permitidos até 1856 (Reis, 1998). Antes desta proibição, muitas foram as recomendações dos físicos ${ }^{3}$ para que fosse decretada a proibição e transferência dos enterros para cemitérios na periferia da cidade, dentro de um grande projeto de saneamento das áreas urbanas (Machado et al., 1978). Data de 1836 um decreto municipal proibindo os enterros dentro do perímetro urbano de Salvador, porém a sua execução foi adiada por mais duas décadas graças às reações de protestos da população, evento que ficou conhecido como Cemiterada (Reis, 1991). Em 1855, uma terrível epidemia de cólera morbo, que pode ter atingido a cifra de 50 mil mortes, afastou definitivamente os cemitérios da cidade (Barbosa, 1972).

Antes disso, era permitido a todos que fossem enterrados no interior das igrejas, mas por serem as covas muitas vezes pagas, geralmente a população pobre e escrava era enterrada no adro, local onde foram achados os exemplares apresentados neste trabalho. Durante o período colonial, que cobre a maior parte da história da Sé, as etnias numericamente mais representadas na população de Salvador eram africanas, só vindo a ocorrer sua redução proporcional na população após a proibição do tráfico de escravos, em meados do século XIX (Verger, 1987). Desta forma o número de enterros de escravos na área do entorno das igrejas era alto, sendo até hoje esta uma cidade com uma população de forte componente afro-brasileiro.

A hipótese de origem amerindia para tais práticas seria muito remota, pois as modificações na América do Sul parecem estar ausentes nas terras baixas e jamais foram mencionadas para os povos arqueológicos conhecidos como Tupiguarani, grande grupo indigena com quem os primeiros europeus travaram continuado contato e fizeram alianças em diferentes pontos de nosso litoral desde o inicio da colonização do Brasil (Tavares, 2001). Embora cerâmica indígena pré-histórica Tupiguarani tenha sido encontrada junto à parte do material escavado na igreja, sugerindo a ocupação pré-colonial do local, e embora as formas de modificação encontradas na Sé fossem comuns tanto aos povos ameríndios quanto aos

: Título que recebia aquele que se formava na arte da medicina, mas que não exercia a cirurgia, função que competia aos Cirurgiōes, estes que por sua vez não podian curar de medicina (Machado ef al., 1978). 
africanos, as pesquisas bioarqueológicas no Brasil, efetuadas até o presente momento, não mostram a prática da modificação entre nossos indígenas antes do contato com grupos de origem africana (Pereira Filho, 1968). E mesmo entre os grupos indígenas pós-contato, os casos de modificação registrados no Brasil, entre os Tenetehara, Makuxi, Galibi, Karipuna, Pauaxiana, Jauari e Kaingang, parecem restringir-se à forma de modificação chamada de "dentes de piranha", ou seja, o corte dos ângulos mesial e lateral dos incisivos, sempre executada nos quatro incisivos da arcada superior (Cunha, 1968a; Nesi, 1968; Nesi e Queiroz, 1968). Além disso, as marcas escalonadas e sulcadas, verificadas no exame da microscopia da maior parte dos dentes estudados na Sé, são mais compatíveis com a técnica de fraturas sucessivas pelo cinzel, descrito para os africanos (Delfino, 1948), do que com a técnica de limagem ou corte, mais comumente usadas pelos amerindios (Dembo e Imbelloni, 1938).

Por tais razões, os dentes mutilados aqui estudados possivelmente pertençam a individuos de origem africana que habitavam Salvador. De acordo com as fontes históricas, a região da Costa da Mina, especificamente, o Golfo de Benin, foi a região africana de onde a Bahia recebeu a maioria dos seus escravos (Verger, 1987), e onde existiu tal prática (Amaral, 1968). No entanto, não se pode descartar a possibilidade de existirem exemplares da região Congo-angolana ou de Moçambique, já que nessas regiões, de onde a Bahia recebeu uma menor percentagem de seus cativos, também existiu prática mutilatória semelhante (Viana Filho, 1938; Pereira Filho, 1968; Jones, 1992).

Deve-se ainda considerar a hipótese da continuidade desta prática entre os descendentes dos escravos nascidos em nosso território, tal como é assinalada em populações sertanejas do interior baiano, ou entre mestiços e índios aculturados, que poderiam ter aprendido com os escravos de Salvador e adotado tais práticas, como ocorreu com índios do Maranhão (Lima, 1954) e de outros estados do Brasil, anteriormente citados.

No presente caso, portanto, as modificações dentárias encontradas são fortemente sugestivas da presença de sepulturas de africanos na igreja da Sé de Salvador, embora os dentes mutilados até agora descritos, sendo avulsos, não permitam precisar padrões mais detalhados que ajudem a identificar a proveniência étnica específica de tais indivíduos. A presença 
de "crioulos", descendentes de negros escravos nascidos no Brasil, bem como de outros mestiços que tivessem adotado a prática mutilatória, também deve ser considerada, dado que tais situações estão descritas para o Brasil (Lima, 1954). Estudos futuros com análise de aDNA poderão confirmar definitivamente o proposto.

\section{Considerações finais}

Este artigo analisou os dentes mutilados recuperados na escavação da antiga Catedral da Sé, de Salvador, com o intuito de informar o achado, descrever as formas mutiladas existentes, verificar as técnicas de modificação empregadas e tentar levantar subsidios histórico-arqueológicos para identificação étnica dos indivíduos ali sepultados.

Os dados obtidos a partir do material estudado e das fontes históricas levantadas permitem propor analogia com a prática da técnica africana de modificação por martelamento sobre cinzel. Embora sejam insuficientes para o estabelecimento preciso de uma filiação étnica, a prevalência de dentes com cicatrizes compatíveis com aquela técnica, somada a uma variedade de formas de modificações, incomum entre os brasileiros, reforça a hipótese de que tais sepulturas seriam de negros, exclusivamente dos nascidos na África.

Este trabalho serviu como primeiro registro de indivíduos com dentes mutilados na região do litoral baiano. No Brasil já existem registros desta prática em populações indígenas (ex.: Tikuna, Tenetehara e Kaingang) e sertanejas (interior da Bahia e outros estados nordestinos), mas o seu registro entre negros, africanos ou brasileiros, ainda é escasso (Cunha, 1968b). Recentemente foi encontrado um esqueleto na região de Canudos que apresentava modificação em forma de "piranha" em três incisivos superiores (o quarto dente incisivo foi perdido post mortem), tendo sido também levantada a hipótese de ser um negro (Robrahn-González e Zanettini, 2001). O investimento em escavações de outros sítios históri-

4 aDNA ou DNA antigo é uma técnica da área da biologia molecular que consiste na extração e amplificação de seqüências residuais de material genético encontradas em amostras biológicas recuperadas nos sítios arqueológicos (Hofreiter et al., 200l). 
cos, fazendo uso de técnicas de datação e análise bioarqueológica, será fundamental para ampliar o conjunto de dados existentes, permitindo uma melhor compreensão desta e de outras questões ligadas à história dos africanos e afro-descendentes na sociedade colonial brasileira.

\section{Agradecimentos}

À Coordenação de Aperfeiçoamento de Pessoal de Nivel Superior (CAPES) pelo financiamento (bolsa de mestrado) do primeiro autor.

Ao Professor Doutor Carlos Etchevarne, vice-diretor do Museu de Arqueologia e Etnologia da Universidade Federal da Bahia (MAE/UFBA) e Chefe do Laboratório de Arqueologia, e à equipe deste Laboratório, pela permissão de estudo do material arqueológico e todo o apoio recebido.

\section{Bibliografia}

Amaral, J. M. 1968. Aspecto histórico da mutilação dentária e sua influência em nossos marinheiros de guerra. Anais da Academia Brasileira de Odontologia (Raridades Bibliográficas de Patronos da Academia), : 191-196.

Andrade, J. C. 1964. Mutilações dentárias (estudo preliminar). Anais da Segzinda Jornada Fluminense de Odontologia "Prof. Coelho e Souza", 2: 65-9.

Barbosa, M. M. A. 1972. Retalhos de un Arquivo. Salvador, Editora Beneditina, Ltda.

Beker, I. 1972. Nomenclatura Biomédica: dental e dentário, derivados. Arquivos Fluminenses de Odontologia, 5 (3): 103-106.

Boccanera Jr., S. 1921. Bahia Histórica. Salvador, Ed. Instituto Geográfico e Histórico da Bahia.

Buikstra, J.; Cook, D. 1992. Paleopatologia. (Sheila M. F. Mendonça de Souza, Trad.)In: Araújo, A.; Ferreira, L. (ed.) Paleopatologia. Paleoepidemiologia. Estudos multidisciplinares. Rio de Janeiro, Escola Nacional de Saúde Pública, Fundação Oswaldo Cruz Panorama : 41-85.

Carneiro, E. 1980. A Cidade do Salvador (1549): uma reconstituição histórica. $2^{\mathrm{a}}$ edição. Rio de Janeiro, Civilização Brasileira.

Cunha, E. S. 1968a. Mutilações Dentária no Negro, no Brasil. Anais da Sexta Jornada Fluminense de Odontologia "Prof. Coelho e Souza", : 19-26. 
Cunha, E. S. 1968b. Considerações sobre Mutilações dentárias no Brasil. Arquivos Fluminenses de Odontologia, 1(3) : 18-24.

Cunha, E. S. 1969. Os Beiço-de Pau: deformações tegumentares e afecções alvéolo-dentárias. Anais da Sétima Jornada Fluminense de Odontologia "Prof. Coelho e Souza",: 20-23.

Delfino, A. 1948. Alteraciones dento-maxilares Intencionales de carácter étnico: nueva classificación. Revista del Museu de la Plata (Nueva serie), 4 (19): 93115.

Della Serra, O.; Ferreira, F. V. 1981. Anatomia Dental. $3^{\text {an }}$ ed. São Paulo, Editora Artes Médicas Ltda.

Dembo, A.; Imbelloni, J. 1938. Deformaciones intencionales del cuerpo humano de carácter étnico. HUMANIOR, Biblioteca del Americanista Modemo. Buenos Aires, Jose Anesi.

Etchevarne, C.; Sousa, A. C.; Palermo Neto, F. 1999. Sítio Antiga Igreja da Sé: relatório da primeira etapa do plano de intervenções arqueológicas. Salvador, Museu de Arqueologia e Etnologia/Universidade Federal da Bahia.

Fastlicht, S. 1948. Tooth Mutilations in Pre-columbian Mexico. Journal of the American Dental Association, 36 (3): 315-23.

Gray, H. 1995. Gray Anatomia. Rio de Janeiro, Guanabara Koogan.

Hofreiter, M.; Serre, D.; Poinar, H.N.; Kuch, M.; Pääbo, S. 2001. Ancient DNA. Nature Reviews Genetics, 2: 353-359.

Jones, A. 1992. Tooth Mutilation in Angola. British Dental Journal, 19:177-9.

Koganei, Y. 1921-22. Über die künstliche Deformation dês Gebisses bei den Steinzeitmenschen Japans. Mitteilungen ats der Medizinischen Fakultat der Kaiserlichen Universitat zu Tokvo, 28: 429-85.

Lima, P. E. 1954. Deformações tegumentares e mutilação dentária entre os Índios Tenetehára. Boletim do Museu Nacional, 16: 1-22.

Machado, R.; Loureiro, A. ; Luz, R. ; Muricy, K. 1978. Danação da Norma: medicina social e constituição da psiquiatria no Brasil. Rio de Janeiro, Edições Graal.

Nesi, W. 1968. Mutilação Dentária em Silvícolas de Roraima. Arquivos Fluminenses de Odontologia, 1 (3): 8-14.

Nesi, W. 1969. Contribuição ao estudo das mutilações dentárias: aspectos patológicos. Anais da Sétima Jornada Fluminense de Odontologia "Prof. Coelho e Souza", : 38-49.

Nesi, W.; Queiroz, V. 1968. Mutilações dentárias. Anais da Sexta Jornada Fluminense de Odontologia "Prof. Coclho e Souza", : 67-70. 
Peixoto, A. 1980. Breviário da Bahia. Rio de Janeiro, Conselho Federal de Cultura.

Pereira Fillho, A. G. 1968. A mutilação dos dentes. Anais da Academia Brasileira de Odontologia (Raridades Bibliográficas de Patronos da Academia), : 178 180.

Peres, F. R. 1974. Memorial da Sé. Salvador, Empresa Gráfica da Bahia.

Reis, J. J. 1991. A Morte É Uma Festa: ritos finebres e revolta popular no Brasil do século XIX. São Paulo, Companhia das Letras.

Reis, J. J. 1998. O Cotidiano da Morte no Brasil Oitocentista. In: Novais, F. A. (coord.); Alencastro, L. F. (org.). História da Vida Privada no Brasil. $3^{3}$ reimpressão. Volume 2. São Paulo, Companhia das Letras.

Robrahn-González, E. M.; Zanettini, P. E. 2001. Arqueologia e Reconstituição Monumental do Parque Estadual de Canudos: salvamento arqueológico do vale da morte (relatório). Revista Camudos, 5 (1/1): 55-96.

Rodrigues-Carvalho, C.; Mendonça-de-Souza, S. M. F. 1998. Uso de adomos labiais pelos construtores de Sambaqui de Cabeçuda, Santa Catarina, Brasil: uma hipótese baseada no perfil dento-patológico. Revista de Arqueologia, $11: 43-55$.

Romero, J. 1958. Mutilaciones Dentarias: prehispánicas de mexico y america en geral. México D. F., Instituto Nacional de Antropologia e Historia. Série Investigaciones 3 .

Rubin de la Borbolla, D. F. 1940. Types of tooth mutilation found in Mexico. American Journal of Physical Anthropology, 26: 349-65.

Santos, J. Norberto R. dos 1962. Mutilações dentárias em pretos de Moçambique. Garcia de Orta, 10 (2): 263-282.

Souza, A. M. 1997. Dicionário de Arqueologia. Rio de Janeiro, ADESA.

Tavares, L. H. D. 2001. História da Bahia. São Paulo, Editora UNESP.

Verger, P. 1987. Fluxo e refluxo do tráfico de escravos entre o Golfo de Benin e a Bahia de Todos os Santos dos séculos XVII à XIX. 3" ed. São Paulo, Currupio.

Viana Filho, L. 1938. O Negro na Bahia. Rio de Janeiro, Editora Livraria José Olympio. 